\title{
Practice of Life Education Based on the Cultivation of Core Literacy
}

\author{
Hanguo Dan \\ Chongqing Jiangbei Middle School, Chongqing 400714, China \\ Email: 83980764@qq.com
}

\begin{abstract}
Education signifies the promotion of the growth of human life. In 2016, Professor Lin Chongde's team of Beijing Normal University released the System of "Chinese Students' Development of Core Literacy", which clarified the basic requirements for students' development of core literacy and provided a guideline for the effective implementation of quality-oriented education. People enjoy natural quality, social quality and spiritual quality. In the process of improving people's core literacy, people's quality of life is also constantly developing. Life education focusing on the cultivation of students' core literacy is an important way to effectively improve students' core literacy, improve students' life quality and effectively implement quality education.
\end{abstract}

Keywords: core literacy, life education, practice

Life education, as an educational idea and a systematic educational theory, has been extensively exercised and explored in the world for more than half a century. In China, Hong Kong and Taiwan are the places to carry out life education at the earliest time, and the practice and exploration of life education in the inland is at a relatively late phase. In recent years, with the occurrence of some undesirable social phenomena such as disregard for life, contempt for life and mutilation of life and under the attention of the Party and the state, the relevant research institutions in colleges and universities take the lead in carrying out research on life education, and promote it in primary and secondary schools. In 2010, the Outline of The National Medium - and Long-term Education Reform and Development Plan (2010-2020) was issued, which clearly proposed in the strategic theme that we should "learn to live" and "pay attention to safety education, life education, national defense education and sustainable development education. "It can be seen that life education has become a strategic decision of the national education development, which is also the first time that the content of "learn to live" and "life education" has been included in the national education reform document, which has far-reaching historical significance. However, there is no unified standard and consensus about how to carry out life education and how to position the goal of life education. In the practice and exploration of life education, there is an expectation to seek bright guidance in the dark night. Such guidance should be based on the development needs of human quality and the essential attributes of education.

\section{The origin of human development and education}

\subsection{Human development}

What are "people" and "human development" about?Marx said in his description of the basic characteristics of the "complete man" that man is the unity of nature, society and spirit. Man is an organism composed of natural factors, social factors and spiritual factors. Human development is the development of natural quality, social quality and psychological quality on the basis of social practice, and the development of human personality on the basis of the comprehensive effect of various human qualities. From this scientific judgment, we should realize two points: At the utmost, there are three kinds of human life, natural life, social life and spiritual life. These three kinds of life organically constitute human life, and the growth of human life is the coordinated growth of natural life, social life and spiritual life. Secondly, human development denotes the coordinated development of natural quality, social quality and spiritual quality (psychology). A well-developed person should have good psychological quality, sound personality and healthy body and mind. Good social quality, know gratitude and responsibility;Good natural quality, can cherish life, learn to live. From the judgment of human nature and human development, we have made clear the origin, direction and future of education.

\subsection{The purpose of education}

The beginning of education is for life. Education is born with the needs of human growth. In the process of human growth and development, human civilization and culture need to be inherited, which requires education. Through education, human development can gain more human experience. UNESCO pointed out in its "Learning to Be" report that the purpose of education is to make man become himself, to "become himself". The essence of modern education lies in the pursuit of 
good quality of life. This shows that education is to make people become "his own". To make a person become himself is to respect his own life, to fully develop and perfect his own potential natural quality, social quality and psychological quality. In 2016, UNESCO published in Rethinking Education: Towards a Global Common Good that "education is the right of human survival and development, and education should respect life, justice and equality". This report regards education as a basic human right, and puts "respect for life" in a more prominent position. It further specifies the purpose and mission of education. Oriental poet Tagore said, the purpose of education should be to transmit the breath of life to people!Starting from the origin of education, the purpose of education is to respect life.

\subsection{Objectives of education}

The ultimate goal of education is to enable people to live a happy life. The former Soviet union educator Suhomlinsky said: "The syllabus and textbooks prescribe all kinds of knowledge for students, which fail to prescribe the most important thing for students, that is, happiness. Our educational belief should be: To cultivate real people and to make every man who has been trained from his own hands live a happy life. "From the pursuit of the original value of education, happiness is the ultimate goal of education. In Rethinking Education: Towards a Global Common Good, the report further states that "education should enable people to lead a life of dignity and happiness". Through education, people can fully develop their own quality, master survival skills and learn to live a happy life. Therefore, the essence of education is to respect life, promote people's development, and make them become a complete and happy person. This kind of human development is the development of human's natural quality, social quality and psychological quality, through the cultivation of these qualities, promote the growth of students' natural life, social life and spiritual life.

Life is the starting point of education, education should return to its origin. Respecting life and promoting human development is the origin and destination of education. How can one become a dignified and happy person?Life education, as the foundation of people's happy life, cannot but respond to this problem!

\section{Quality of life and core literacy}

\subsection{Value orientation of education in the new era}

Since the Third Plenary Session of the 18th CPC Central Committee, we have made great efforts to deepen comprehensive reform in the field of education, and the national education development strategy has undergone fundamental changes, which are mainly reflected in the following aspects: First, we have adjusted the theme of education strategy and paid more attention to the quality of education. During the 13th Five-Year Plan period, education quality has become the strategic theme of education in the new era, which has changed from focusing on education equity to improving education quality during the 12th Five-Year Plan period. This kind of education quality is a kind of comprehensive education quality, which pays more attention to the cultivation of students' moral quality, physical and mental health, innovative quality and practical ability. We believe that the core of improving the quality of education is to improve the quality of students' life, pay attention to the development of students' natural quality, social quality and spiritual (psychological) quality, and improve the quality of students' natural life, social life and spiritual life. Second, from the perspective of quality education, the core accomplishment system of students is put forward, and the core connotation and target requirements of quality education are further clarified. In September 2016, the Ministry of Education released the Index system of Chinese Students' Development Core Literacy at Beijing Normal University. This system consists of three aspects: cultural foundation, independent development and social participation, including six dimensions: "cultural foundation, scientific spirit, learning to learn, healthy life, responsibility, practice and innovation", and defines eighteen key performances.

\subsection{Students' life quality is the top priority of education}

Li Xigui, principal of Beijing National Day School, said in his book 36 Days: My Journey to American Education that "education is the whole process of improving the quality of one's life. ". It clearly put forward that education should pay attention to the quality of students' life. As far as the concept of quality of life itself is concerned, it is the quality state of natural quality of individual life measured and evaluated according to certain social standards, also known as quality of life, quality of life. Quality of life (HRQOL) was originally a sociological concept. Later, research on quality of life was widely carried out in the medical field to explore the influence of diseases and treatments on quality of life, and the concept of health related quality of life (HRQOL) was formed. From the perspective of life education, we believe that the quality of life is not only the natural quality of individual life quality status, it also includes social quality, psychological quality, the quality of state, is a based on the natural quality, social quality and psychological quality coordinated development of comprehensive quality standards, is the person's natural life quality, the unity of social life and spiritual life quality. Life education is a 
process of promoting the growth of human life and improving the life quality of students through education. This quality of life is related to the cultivation of students' core accomplishment, overall quality development and the cultivation of happy life skills.

\subsection{Core literacy is the core of life education}

From the perspective of the composition of students' core accomplishment system, life education and core accomplishment cultivation are closely linked and integrated. It can be said that core literacy is the pursuit of the core value of life education, and life education is the key way to cultivate core literacy.

First of all, the three aspects of core literacy correspond to the three qualities of life education. We believe that "independent development" of core literacy corresponds to "natural quality" of students, "cultural foundation" corresponds to "spiritual quality" of students, and "social participation" corresponds to "social quality" of students. "Independent development" requires students to "learn to learn and live a healthy life", which is to pay attention to the requirements of human life growth from the perspective of natural life and meet the basic needs of human survival and development. "Cultural foundation" requires students to have "humanistic background and scientific spirit", which requires students to develop scientific quality, have humanistic quality, healthy body and mind, sound personality, and be a healthy person of spiritual life from the perspective of spiritual life. "Social participation" enables students to "take responsibility, practice and innovate", which puts forward the social responsibility and ability preparation that a person in a social sense should have from the perspective of social life.

Secondly, people's quality characteristics and the key performance of core accomplishment are consistent with each other. Man's natural qualities from man's anatomy shown in mentality and physiology characteristic, mainly reflected in the sports quality, response speed, adaptability and resistance to learn to survive, understand the basic quality of life, in the core literacy system's "cherish life, self management, willing to learn, and reflection" elements such as is the concentrated reflection of man's natural qualities. Human social quality mainly includes scientific culture (language, mathematical logic knowledge and skills, scientific theoretical belief, world outlook, etc.), political morality, labor aesthetics, etc. , which mainly reflects the key quality of human social attribute. In the core accomplishment system, "labor consciousness, problem solving, technology application, social responsibility, national identity, international understanding" and other elements are the concentrated embodiment of human social quality.

Human spiritual quality mainly includes intellectual factors and non-intellectual factors (motivation, interest, will, character, etc. ) and other aspects of personality quality and psychological quality. In the core accomplishment system, such elements as "sound personality, rational thinking, critical questioning, courageous inquiry, aesthetic taste and humanistic feelings" are the concentrated embodiment of human spiritual quality. Therefore, from the perspective of the three qualities of people, they are well reflected in the core accomplishment system. It can be said that the core accomplishment system of Chinese students is constructed and designed closely around the natural quality, social quality and spiritual quality of students' life growth, which meets the needs of human life growth and essential quality development. While life education is exploring and practicing the cultivation of these qualities for students for a long time, the core accomplishment naturally becomes the core value pursuit of the goal of life education.

Now we can answer the question of how to make a person a dignified and happy person. A person with good core qualities must have a high quality of life and live a dignified and happy life. To enable everyone to have a dream, and pursue dignity and happiness of life, this is our life educators educational mission. It is the realistic responsibility of life education to improve the quality of education, pay attention to the quality of students' life and strengthen the cultivation of core accomplishment.

\section{Practical strategies to promote life education}

Our school takes the lead in creating the "Four Modernizations Model" of life education in China, that is, developing life-oriented school-based curriculum, creating life-oriented classroom teaching, carrying out life-oriented education activities and building life-oriented campus culture. The construction of "ecological morality" has been integrated into the construction of campus culture, and an open life education hall has been built, thus forming a curriculum system combining dynamic development of implicit and explicit courses. Centering on the cultivation of students' core qualities, the schoolbased practice of life education has been vigorously promoted.

\subsection{Creation of life-oriented classroom teaching}

The construction of green, ecological and life classes is the basis and premise of life education. In the implementation of life education, the school takes the lead in carrying out classroom teaching reform, abandoning traditional teaching 
concepts, respecting students' individual life needs, meeting the education proposition of students' individual development, and constructing an open, democratic, harmonious, vivid and humanistic classroom teaching environment. To strengthen the infiltration of life education in subject teaching, teachers should fully explore the curriculum content and theme closely related to life education in the course of subject teaching, explain and sublimate from the Angle of human natural life, spiritual life and social life, and actively guide students to understand life, respect life and cherish life.

\subsection{Education activities with life-oriented campaigns}

We extensively organize and carry out a variety of student activities based on life education, adhere to the student associations as the main body, enrich students' life experience and perception so as to enable students to know the meaning and value of life in the activities. Through carrying out the school theme education activities, the subject life education activities are carried out sequentially and step by step, which include the implementation of home-school co-education activities and to give play to the positive role of family education, the implementation of research travel activities, to give full play to the influence of life education base.

\subsection{Development of life-oriented school-based curriculum}

Curriculum is the key carrier to realize educational idea and value goal. The implementation of life education, without the support of curriculum, can not really give its play. We explored the establishment and implementation of the schoolbased curriculum system of school life education based on the national curriculum, and developed and applied the schoolbased curriculum of "Ten Ten" "Understanding of Life". Ten chapters are selected for each subject to correspond to the three themes of natural life, social life and spiritual life, and the teaching material system of life education is constructed from five aspects: guidance hints, research content, content appreciation, appreciation and sublimation, and reflection after learning. The "sublimation of appreciation" part is mainly based on the chapters of the subject, which excavates one or several educational connotations of natural life, social life and spiritual life, and discusses the life education.

\subsection{Building a life-oriented campus culture}

According to the concept of "life education", the school carries out reasonable renovation, planning and layout of the school environment, which strives to build the school into a humanized warm home that can not only reflect humanistic care, but also play the role of edification and infection - life education based ecological park. The campus's each block walls can talk, every tree flowers and plants can be silent teacher, and every corner of the campus is safe and comfortable, which is conducive to the healthy growth of students, so as to promote the continuous improvement and improvement of students' life development.

\section{References}

[1] Luo Ting. The cultivation of medical students' sense of life meaning from the perspective of positive psychology[J]. Modern Business Trade Industry, 2021, 42(30): 41-43.

[2] Liu Wenda. Research on life education in biology course teaching[J]. Way of Success, 2021(26): 117-119.

[3] Shi Kejing. Research on the dilemma and countermeasures of life education in colleges and universities[J]. Policy Research \& Exploration, 2021(08): 90-91.

[4] Wang Shuqin, Yang Zilin. Research on teaching strategy of physics in senior high school from the perspective of core literacy[J]. Study, 2021 (36) : 13-14.

[5] Wei Yongxi. Research on Chinese reading teaching in primary and secondary schools based on the cultivation of core literacy[J]. Learning Weekly, 2021(28): 81-82.

[6] Luo Ting. The cultivation of medical students' sense of life meaning from the perspective of positive psychology[J]. Modern Business Trade Industry, 2021, 42(30): 41-43.

[7] Shi Yan, Tang Qiyuan. Integration of core literacy into gender equality education curriculum construction[J]. Journal of China Women's University, 2021, 33(05): 72-77. 